\title{
Estimated Glomerular Filtration Rate Increases in Chronic Hepatitis B Patients Treated With Telbivudine Monotherapy and Combination Treatment
}

\author{
Libin Jiang, Song Hu, Man He, and Deying Tian ${ }^{1}$, \\ ${ }^{1}$ Department of Gastroenterology, Tongji Hospital, Tongji Medical College, Huazhong University of Science and Technology, Wuhan, China \\ *Corresponding Author: Deying Tian, Department of Gastroenterology, Tongji Hospital, Tongji Medical College, Huazhong University of Science and Technology, Wuhan, China. Tel: \\ +86-2783663268; +86-13707184968, E-mail: dytian@tjh.tjmu.edu.cn
}

Received 2015 August 18; Revised 2015 November 23; Accepted 2015 November 23

\begin{abstract}
Background: Several studies have reported a renoprotective effect of telbivudine during the treatment of patients for chronic hepatitis $\mathrm{B}(\mathrm{CHB})$.

Objectives: This longitudinal retrospective study aimed to examine the effects of telbivudine monotherapy and combination therapy (adefovir plus telbivudine) on renal function.

Patients and Methods: This study included 336 Chinese CHB patients, who were selected from outpatients in Tongji Hospital. 44, 122, 66, 58 , and 46 of these patients had been orally taking adefovir, telbivudine, entecavir, adefovir plus telbivudine, and adefovir plus lamivudine, respectively, for at least 24 months.

Results: The estimated glomerular filtration rate (eGFR) in the telbivudine and adefovir plus telbivudine groups increased by $5.14 \mathrm{~mL} / \mathrm{min}$ $(\mathrm{P}<0.001)$ and $6.19 \mathrm{~mL} / \mathrm{min}(\mathrm{P}=0.005)$, respectively. The patients taking the five drug regimens were further grouped into the following three subpopulations: those with compensated hepatic cirrhosis, those aged 50 or more years, and those with baseline eGFR values of $50-90 \mathrm{~mL} / \mathrm{min}$. The three subgroups that received telbivudine monotherapy exhibited eGFR increases of $6.38,6.74$, and $10.82 \mathrm{~mL} / \mathrm{min}$, respectively. The three subgroups that received combination therapy of adefovir plus telbivudine exhibited eGFR increases of $18.31,14.73$, and $16.59 \mathrm{~mL} / \mathrm{min}$, respectively $(\mathrm{P}<0.05)$. The predictive factors for the change in eGFR levels over time were analyzed by means of two linear mixed effects models for the three monotherapy regimens and two combination regimens. Age, gender, and medication are predictive factors of eGFR changes. In addition, abnormal creatinine kinase (CK) levels in the telbivudine group were not correlated with eGFR changes $(\mathrm{P}=0.992)$.

Conclusions: These findings indicate that telbivudine, used in both monotherapy and combination therapy, improves the renal function of patients with CHB. The improvements are particularly significant in patients at high renal risk.
\end{abstract}

Keywords: Hepatitis B, Chronic, Glomerular Filtration Rate, Telbivudine, Adefovir

\section{Background}

Chronic hepatitis B virus (HBV) infection is a major public health burden. Approximately one-third of the world's population has serological evidence of past or present infection with $\mathrm{HBV}$, and 350 to 400 million people are chronic hepatitis B surface antigen (HBsAg) carriers (1). This chronic infection can last for decades or a lifetime. Thus, the control of HBV-induced liver injury is an important objective. The goal of therapy for chronic hepatitis $\mathrm{B}(\mathrm{CHB})$ is to prevent the disease from developing into decompensated cirrhosis, end-stage liver disease, hepatocellular carcinoma, and even death, thereby improving quality of life and extending lifespan $(1,2)$. Currently, the only way to achieve this objective is through the prolonged suppression of HBV replication. Accordingly, oral administration of antiviral drugs is a key strategy.

Five oral antiviral drugs have been approved for the treatment of $\mathrm{CHB}$, including two nucleotide analogues (adefovir and tenofovir) and three nucleoside analogues (lamivudine, telbivudine, and entecavir) $(1,3)$. These drugs are safe and simple to take (one pill per day) and can effectively inhibit HBV replication, making long-term antiviral therapy possible for CHB patients. Nevertheless, increasing numbers of patients require long-term antiviral treatment, and the need for combination therapy is also increasing. The question of the safety of this chronic drug use is drawing public attention. These five drugs are metabolized by the kidneys (4), and renal safety must therefore be considered.

It has been reported that adefovir exhibits dose-related renal toxicity during $\mathrm{CHB}$ treatment. After 48 weeks of therapy, the incidence of renal toxicity is 13,27 , and $50 \%$ at daily doses of 30,60 , and $120 \mathrm{mg}$, respectively (5). When

Copyright ( 2016, Kowsar Corp. This is an open-access article distributed under the terms of the Creative Commons Attribution-NonCommercial 4.0 International License (http://creativecommons.org/licenses/by-nc/4.0/) which permits copy and redistribute the material just in noncommercial usages, provided the original work is properly cited. 
Jiang L et al.

the dose is low (10 mg/day), the renal toxicity manifests as a slight increase in the serum creatinine (SCr) level and a decrease in the serum phosphate level (6). Renal toxicity has also been seen when adefovir has been used in combination with lamivudine for HBV infection treatment. In a study involving 145 lamivudine-resistant patients, $7 \%$ of patients required adjustment of their adefovir dosage because of renal toxicity, but no one had to discontinue the therapy (7). Tenofovir use for HIV and HBV co-infection also leads to SCr elevation and renal impairment $(8,9)$. In contrast, a multi-center study indicated that telbivudine improves renal function (10). It was also reported that telbivudine in combination with adefovir can increase the estimated glomerular filtration rate (eGFR) (11). However, it was less convincing to compare the patients in combination therapy group and monotherapy group in this study, probably because the patients in the combination therapy groups had previous exposure to one antiviral drug. Accordingly, they may have suffered subclinical renal toxicity during the previous exposure.

Chronic HBV infection itself can also cause renal impairment. A recent study involving 260 chronic carriers of HBsAg revealed that $64.6 \%$ of them suffer from renal dysfunction (12). Epidemiological data indicate that some CHB patients develop hepatitis B virus-associated glomerulonephritis (HBV-GN), which primarily manifests as membranous nephropathy (13). Compared with other antiviral drugs, telbivudine is often accompanied by an increase in the CK level. The level usually normalizes after reduction of the dose or the administration of coenzyme Q10 (14). The increases in creatinine kinase (CK) levels that are uniquely attributable to telbivudine may somehow correlate with its specific renoprotective effect.

\section{Objectives}

To address these questions, this clinical study analyzed the change of eGFR in patients treated with different antiviral regimens. In addition, the potential correlation of abnormal CK levels in the telbivudine group with the eGFR change was also evaluated.

\section{Patients and Methods}

\subsection{Patients}

This clinical longitudinal retrospective analysis involved a total of $411 \mathrm{CHB}$ patients who received antiviral treatment from July 2011 to June 2014 without interruption for at least two years. All patients were outpatients of Tongji Hospital, which located in Wuhan, China. The eligible patients comprised three monotherapy groups and two combination therapy groups based on their oral medications (Figure 1). Patients in the monotherapy groups received adefovir (10 mg/d), entecavir ( $0.5 \mathrm{mg} / \mathrm{d})$, or telbivudine $(600 \mathrm{mg} / \mathrm{d})$. Patients in the combination treatment groups were prescribed adefovir $(10 \mathrm{mg} / \mathrm{d})$ combined with either telbivudine $(600 \mathrm{mg} / \mathrm{d})$ or lamivudine $(100 \mathrm{mg} / \mathrm{d})$. All of the patients completed their treatment regimen for a minimum duration of two years. Patients were enrolled when they commenced their treatments, and the terminal point was defined as two years after treatment initiation. No adjustments of dosage were made during the treatment period, and the patients presented for re-examination every three months. No deaths or poor virological responses occurred during the treatment period.

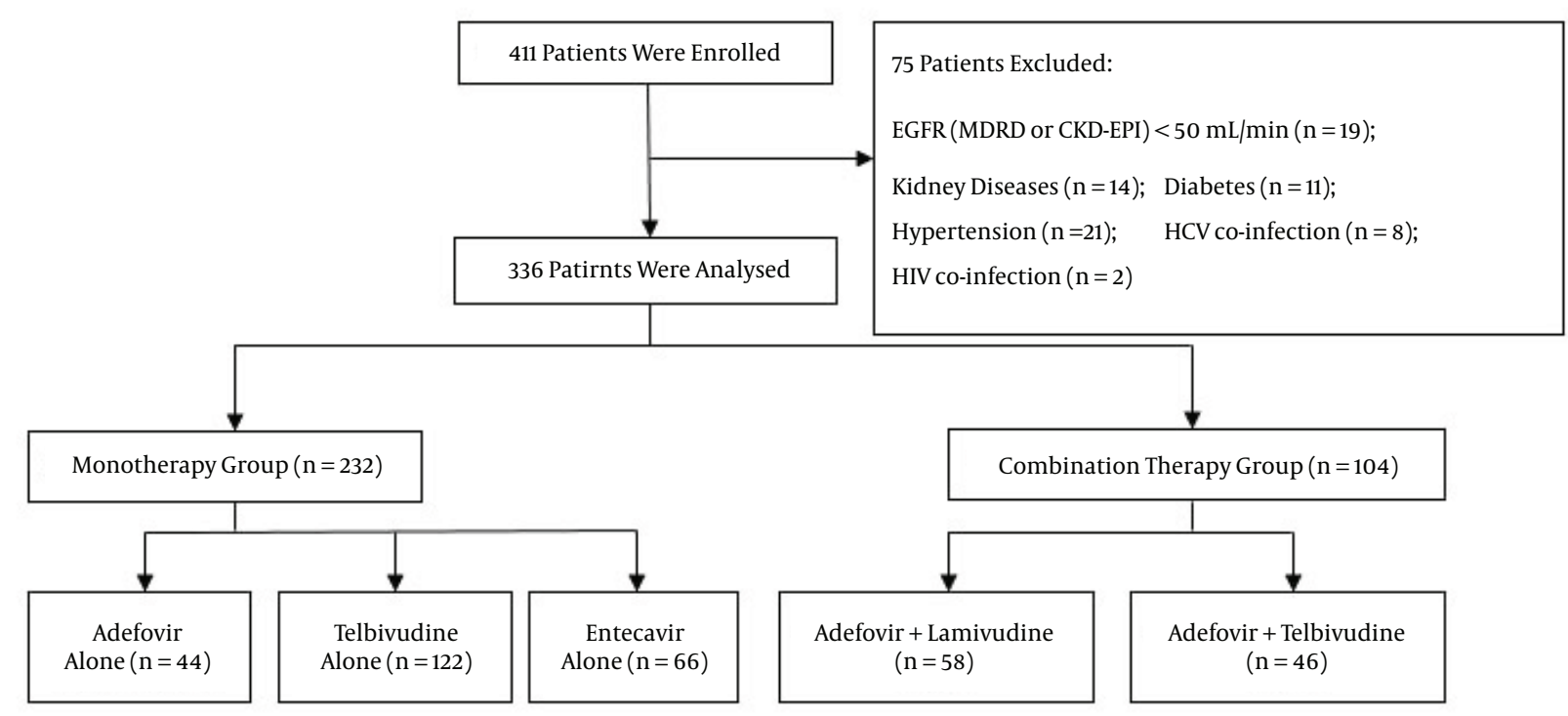

Figure 1. Flow Chart of Study Patient 
Jiang L et al.

All patients in the monotherapy groups received initial antiviral treatments based on the clinical practice guidelines of the European Association for the Study of the Liver (EASL) (1). Patients in the two combination groups had been taking lamivudine or telbivudine as monotherapy, but drug resistance was evidenced by partial virological response or virological breakthrough. Accordingly, adefovir was added as a second drug in combination with the first. Partial virological response was defined as a detectable HBV DNA level after at least 6 months of therapy in compliant patients despite a decrease in HBV DNA of more than $1 \log 10 \mathrm{IU} / \mathrm{mL}$. The definition of virological breakthrough was a confirmed increase in the HBV DNA level of more than 1 log10 IU/mL from the lowest HBV DNA level during therapy (1).

A high load of HBV DNA or deposition of HBsAg on the glomerular basement membrane (GBM) may have an impact on renal function $(15,16)$. Therefore, patients who had never received any treatment were not enrolled as a control group, nor were inactive HBsAg carriers enrolled. Lamivudine and telbivudine can effectively suppress HBV replication (17), and the viral inhibition may potentially affect renal function. For this reason, patients receiving monotherapy and those receiving combination therapy were not grouped together for comparisons. Patients suffering from kidney diseases, diabetes, hypertension, HIV, and/or HCV infection were excluded, as were patients whose baseline eGFR was lower than $50 \mathrm{~mL} / \mathrm{min}$ as such an eGFR level requires a reduced dosage of antiviral drugs (1). In addition, Patients with decompensated cirrhosis were also not included in our study for they were more prone to hepatorenal syndrome, which was life-threatening. Decompensated cirrhosis was determined with comprehensive consideration of clinical signs and symptoms and laboratory parameters (18).

\subsection{Data Collected}

All data were collected from the patients' medical files, including their age, gender, medication, and the presence of compensated liver cirrhosis. Compensated liver cirrhosis was diagnosed through imaging modalities (color ultrasound, computed tomography, or magnetic resonance imaging), an instantaneous elasticity scan, or fibrosis-related blood tests (hyaluronic acid, laminin, procollagen III, or type IV collagen). Data related to HBV infection were collected from the patients' return visits and included HBV serological markers, HBV DNA, and HBV drug-resistant loci. Biochemical markers included serum alanine aminotransferase (ALT), SCr, and CK. The CK level in the telbivudine monotherapy group was measured every six months and checked for abnormality by an appropriate criterion (CK > $191 \mathrm{U} / \mathrm{L}$ for males and CK > $171 \mathrm{U} / \mathrm{L}$ for females). As judged by muscle symptoms, myositis, and rhabdomyolysis, myopathy was not found in patients treated with telbivudine.

\subsection{Serological and Biochemical Detection}

Serum alanine aminotransferase (ALT) levels were measured using the IFCC method with an autoanalyzer (Roche cobas® 8000). Values of ALT $>41 \mathrm{U} / \mathrm{L}$ and $>40 \mathrm{U} / \mathrm{L}$ in male and female patients, respectively, were regarded as elevated. Serum creatinine was detected using Roche COBAS C501 automatic biochemical analyzer and its normal range was $59 \sim 104 \mu \mathrm{mol} / \mathrm{L}$. Serum levels of HBV DNA were quantified using a real-time PCR assay with a Roche LightCycler® 480 analyzer; the lower detection limit was 500 copies/mL.

\subsection{Assessment of Renal Function}

The SCr level is detected on routine blood testing, but GFR (which is clinically difficult to directly measure) is a more sensitive and informative marker of renal function (19). Therefore, the following SCr-based formulas were used to estimate GFR:

1) the abbreviated Modification of diet in renal disease (aMDRD) equation for eGFR was the following (19):

EGFR $\left(\mathrm{mL} / \mathrm{min} / 1.73 \mathrm{~m}^{2}\right)=175 \times$ creatinine $(\mathrm{mg} / \mathrm{dL})^{-1.154} \times$ age $^{-0.203} \times 0.742$ (if female)

2) the Chronic Kidney Disease Epidemiology Collaboration (CKD-EPI) equations were the following (20):

For females with creatinine levels $\leq 0.7 \mathrm{mg} / \mathrm{dL}$, eGFR $=$ $144 \times(\text { creatinine } / 0.7)^{-0.329} \times(0.993)$ age;

For females with creatinine levels $>0.7 \mathrm{mg} / \mathrm{dL}$, eGFR $=$ $144 \times(\text { creatinine } / 0.7)^{-1.209} \times(0.993)$ age;

For males with creatinine levels $\leq 0.9 \mathrm{mg} / \mathrm{dL}, \mathrm{eGFR}=141$ $\times(\text { creatinine } / 0.9)^{-0.411} \times(0.993)$ age;

For males with creatinine levels $>0.9 \mathrm{mg} / \mathrm{dL}, \mathrm{eGFR}=141$ $\times(\text { creatinine } / 0.9)^{-1.209} \times(0.993)^{\text {age }}$.

According to kidney-related guidelines, patients are categorized as having either normal renal function (eGFR $\geq$ $90 \mathrm{~mL} / \mathrm{min}$ ) or slightly impaired renal function (eGFR $\geq$ 60 but less than $90 \mathrm{~mL} / \mathrm{min}$ ) (19). However, in this study of chronic hepatitis B, renal function was considered slightly impaired when the eGFR was $\geq 50$ but less than $90 \mathrm{~mL} / \mathrm{min}$. A value of $50 \mathrm{~mL} / \mathrm{min}$ was determined to be the cut-off value because patients receiving long-term antiviral treatment need an adjustment of their drug dosage when the creatinine clearance is below $50 \mathrm{~mL} / \mathrm{min}(1)$.

\subsection{Statistical Methods}

Normally distributed continuous variables were represented by means \pm standard deviations and evaluated using t test or analysis of variance method. Continuous variables that were not normally distributed were evaluated using Mann-Whitney U-test or Wilcoxon one-sample test. Categorical variables were reported as percentages and assessed using the chi-square of Fisher's exact test.

Two linear mixed effects models for the monotherapy and combination therapy groups were established to analyze the predictive factors of eGFR changes over time. Fixed effects in these two models included baseline eGFR, age, 
Jiang L et al.

gender, presence of compensated liver cirrhosis, medication, hepatitis B e antigen (HBeAg) state, and drug-time interaction. Random effects were individual differences. Model parameters were estimated using the restricted maximum likelihood method of holistically comparing the likelihood ratio statistics (-2 Log Likelihood), Akaike's Information Criterion (AIC), and Schwarz's Bayesian Criterion (BIC) in different covariance structures. The unstructured covariance matrix (UN) was used in these models.

The last observation carried forward method was used for data missing due to dropouts in this longitudinal clinical study. All statistical analyses were conducted using the SPSS 22.0 software. A P value less than 0.05 on both sides indicated statistical significance.

\subsection{Ethical Approval}

This single-center study was approved by the Ethics Committee of Tongji Hospital (Code: TJ-C20110411; Date: 28/04/2011), Tongji Medical College, Huazhong Univer- sity of Science and Technology. At the time of their enrollment, each patient was informed of the aims of the study, the methodology, and why they were asked to participate. The signed agreements were recorded in the patient's medical files.

\section{Results}

\subsection{Clinical Characteristics at Baseline}

A total of $336 \mathrm{CHB}$ patients were included in this clinical research. They were divided into three monotherapy groups and two combination therapy groups according to the drugs they were taking. As shown in Table 1, the three monotherapy groups did not significantly differ in age, gender, baseline HBeAg, compensated liver cirrhosis, baseline SCr, baseline eGFR, and eGFR classification. As shown in Table 2, the two combination therapy groups also did not show significant differences in these baseline characteristics.

\begin{tabular}{|c|c|c|c|c|}
\hline Characteristic & Adefovir & Entecavir & Telbivudine & P Value \\
\hline Patients, $n$ & 44 & 66 & 122 & \\
\hline Age, $y$ & $39.27 \pm 11.14$ & $40.65 \pm 10.89$ & $38.34 \pm 11.13$ & .392 \\
\hline Male & $34(77.27)$ & $53(80.30)$ & $86(70.49)$ & .304 \\
\hline HBeAg-positive & $24(54.55)$ & $45(68.18)$ & $72(59.02)$ & .302 \\
\hline Compensated cirrhosis & $12(27.27)$ & $18(27.27)$ & $34(27.87)$ & .995 \\
\hline SCr, median(IQR), $\mu \mathrm{mol} / \mathrm{L}$ & $70.50(19.75)$ & $71.50(18.00)$ & $69.50(22.50)$ & .740 \\
\hline eGFR (aMDRD), median(IQR), mL/min & $105.02(29.55)$ & $103.04(22.70)$ & $105.91(22.53)$ & .728 \\
\hline eGFR categories, & & & & .834 \\
\hline$\geq 90 \mathrm{~mL} / \mathrm{min}$ & $36(81.82)$ & $53(80.30)$ & $95(77.87)$ & \\
\hline $50-90 \mathrm{~mL} / \mathrm{min}$ & $8(18.18)$ & $13(19.70)$ & $27(22.13)$ & \\
\hline
\end{tabular}

${ }^{\mathrm{a}}$ Data are presented as mean $\pm \mathrm{SD}$ or No.(\%).

\begin{tabular}{|c|c|c|c|}
\hline Characteristic & Adefovir + Telbivudine & Adefovir + Lamivudine & PValue \\
\hline Patients, $\mathbf{n}$ & 46 & 58 & \\
\hline Age, $y$ & $37.48 \pm 14.02$ & $40.19 \pm 12.43$ & .232 \\
\hline Male gender & $29(63.04)$ & $45(77.59)$ & .354 \\
\hline HBeAg-positive & $29(63.04)$ & $31(53.45)$ & .325 \\
\hline Compensated cirrhosis & $10(21.74)$ & $19(32.76)$ & .213 \\
\hline \multicolumn{4}{|l|}{ Baseline } \\
\hline $\mathrm{SCr}, \operatorname{median}(\mathrm{IQR}), \mu \mathrm{mol} / \mathrm{L}$ & $66.00(14.50)$ & $71.00(20.00)$ & .307 \\
\hline eGFR, median(IQR), mL/min & $97.45(35.12)$ & $101.04(37.45)$ & .922 \\
\hline eGFR categories, n(\%) & & & .531 \\
\hline$\geq 90 \mathrm{~mL} / \mathrm{min}$ & $33(71.74)$ & $38(65.52)$ & \\
\hline $50-90 \mathrm{~mL} / \mathrm{min}$ & $13(28.26)$ & $20(34.48)$ & \\
\hline
\end{tabular}

Abbreviations: eGFR, estimated glomerular filtration rate; HBeAg, hepatitis B e antigen.

${ }^{\mathrm{a}}$ Data are presented as mean \pm SD or No.(\%).

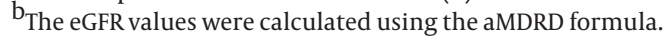


Jiang L et al.

4.2. The eGFR Changes From Baseline to Year 2 in the Five Treatment Groups (Based on the aMDRD Formula)

Regarding the three monotherapy groups, the telbivudine group exhibited an eGFR increase of $5.14 \mathrm{~mL} / \mathrm{min}(\mathrm{P}$ $<0.001$ ), whereas the eGFR in the adefovir and entecavir groups decreased by $5.78 \mathrm{~mL} / \mathrm{min}$ and $3.89 \mathrm{~mL} / \mathrm{min}(\mathrm{P}=$ $0.001)$, respectively, from baseline to year 2. Regarding the two combination therapy groups, the adefovir plus telbivudine group exhibited an eGFR increase of $6.19 \mathrm{~mL} /$ $\min (\mathrm{P}=0.005)$ and the eGFR in the adefovir plus lamivudine group decreased by $4.69 \mathrm{~mL} / \mathrm{min}(\mathrm{P}=0.003)$ during the 2-year therapy period. The results were the same regardless of whether the CKD-EPI or aMDRD equation was used for eGFR, thus indicating that telbivudine improves renal function regardless of whether it is used as monotherapy or combination therapy. Furthermore, groups lacking telbivudine suffered decreased renal function (Figure 2).

Inter-group comparisons indicated that the renal function changes in the telbivudine group were significantly different $(P<0.001)$ from those in the other two monotherapy groups. Furthermore, the eGFR decreases in the adefovir and entecavir groups were comparable (5.78 \pm 10.35 vs. $3.89 \pm 8.87, \mathrm{P}=0.307$ ), and the eGFR changes in the adefovir plus telbivudine group were significantly different from those in the adefovir plus lamivudine group $(+6.19 \pm 14.31$ vs. $-4.69 \pm 11.34, \mathrm{P}<0.001)$ (Figure 2$)$.

\subsection{The eGFR Changes from Baseline to Year 2 in} Special Populations (Baseline eGFR of $50-90 \mathrm{~mL} /$ min, Compensated Liver Cirrhosis, and $\geq 50$ Years Old; Based on the aMDRD Formula)

Patients who suffer from compensated liver cirrhosis or are aged 50 years or more are at a high risk of renal insufficiency. The analysis of these two subgroups in each monotherapy group indicated that the use of telbivudine significantly improves renal function. Specifically, the eGFR values of the patients suffering from compensated liver cirrhosis $(n=34)$ and those of the patients aged 50 years or more $(\mathrm{n}=17)$ increased by 6.38 $\pm 9.79 \mathrm{~mL} / \mathrm{min}(\mathrm{P}=0.001)$ and $6.74 \pm 7.02 \mathrm{~mL} / \mathrm{min}(\mathrm{P}=$ 0.001 ), respectively, in the telbivudine group (Figure 3 ). The analysis of the same subgroups undergoing the two combination therapy drug regimens indicated that the eGFR values of the patients suffering from compensated liver cirrhosis $(n=10)$ and of the patients aged 50 years or more $(\mathrm{n}=10)$ in the adefovir plus telbivudine group remarkably increased by $18.31 \pm 14.02 \mathrm{~mL} / \mathrm{min}(\mathrm{P}=$ $0.003)$ and $14.73 \pm 8.28 \mathrm{~mL} / \mathrm{min}(\mathrm{P}=0.001)$, respectively (Figure 3). These results indicate that the renal function of the patients at high renal risk significantly improved after taking telbivudine. The subgroup analysis of the patients with baseline eGFR values of $50-90 \mathrm{~mL} / \mathrm{min}$ assigned to each of the five drug regimens indicated that the eGFR values of the patients $(n=27)$ in the telbivudine monotherapy group and of the patients $(n=13)$ in the telbivudine combination therapy group increased by $10.82 \pm 7.89 \mathrm{~mL} / \mathrm{min}(\mathrm{P}<0.001)$ and $16.59 \pm 12.78 \mathrm{~mL} /$ $\min (\mathrm{P}=0.001)$, respectively, from the baseline values. Therefore, telbivudine significantly improves the renal function of patients whose initial renal function is slightly impaired (greater than or equal to 50 but less than $90 \mathrm{~mL} / \mathrm{min}$ ).

Figure 2. Changes in Renal Function in the Five Treatment Groups Over 2 Years
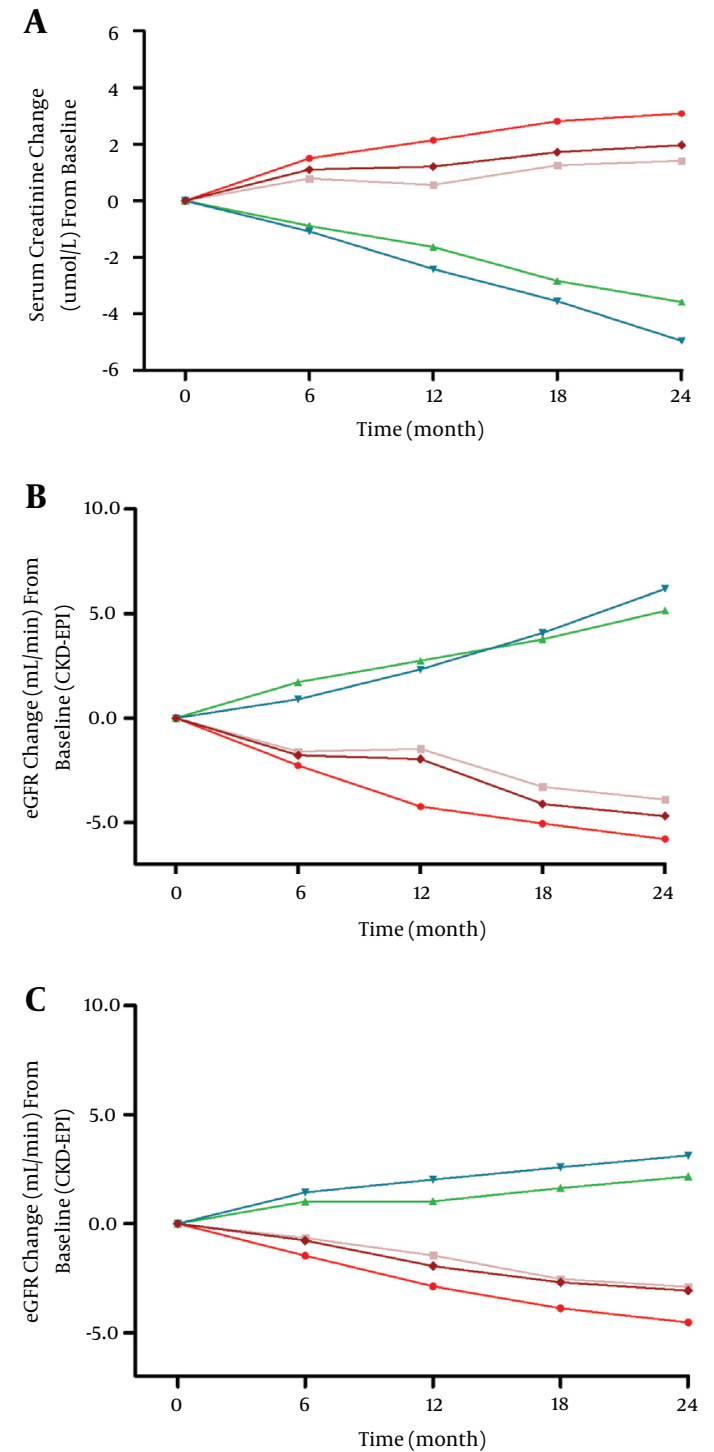

$$
\begin{aligned}
& \rightarrow \text { Adefovir } \\
& \rightarrow \text { Adefovir + Telbivudine }
\end{aligned}
$$

As assessed by: A, SCr; B, eGFR calculated by the CKD-EPI formula; and C, eGFR calculated by the aMDRD formula. 
Figure 3. Changes in eGFR at Month 24 Compared With the Baseline Values in the Different Subgroups

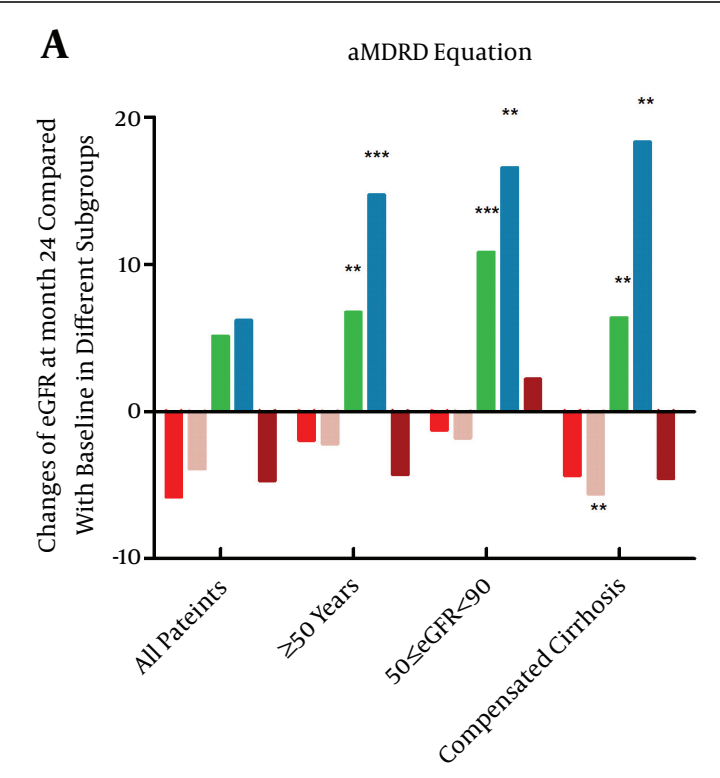

B CKD-EPI Equation

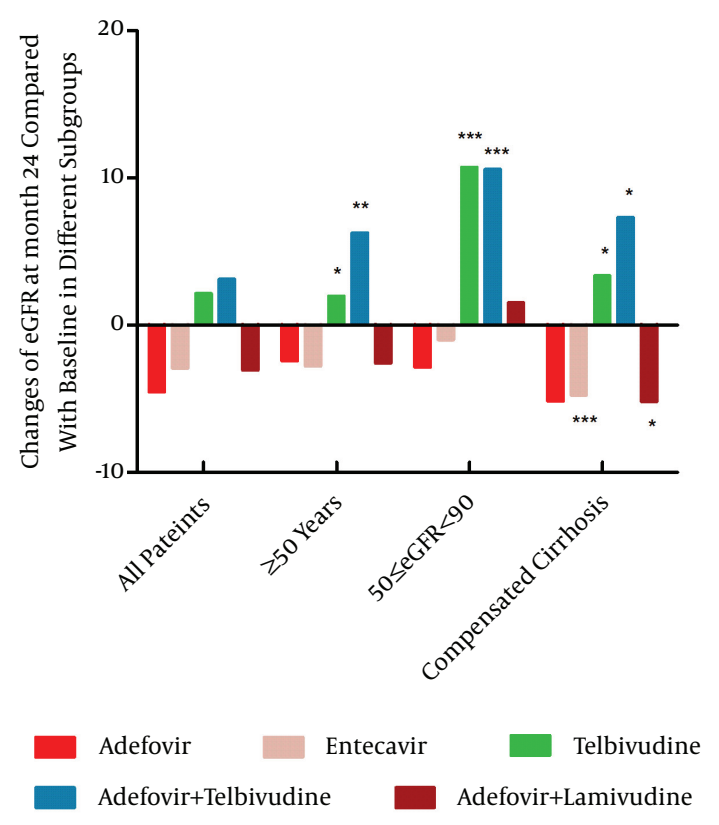

A, eGFR calculated with the aMDRD equation; B, eGFR calculated with the CKD-EPI equation ${ }^{*} \mathrm{P}<0.05 ;{ }^{* *} \mathrm{P}<0.01 ;{ }^{* * *} \mathrm{P}<0.001$.

\subsection{Changes in the eGFR Stratification of Patients Assigned to the Five Drug Regimens Before and Af- ter the 2-year Treatment Period (Based on the aM- DRD Equation)}

The aMDRD formula was selected instead of the CKD-EPI formula because the former better reflects the renal
Figure 4. Shift Table of the eGFR Values (aMDRD method) From Baseline to Year 2 in the Five Groups

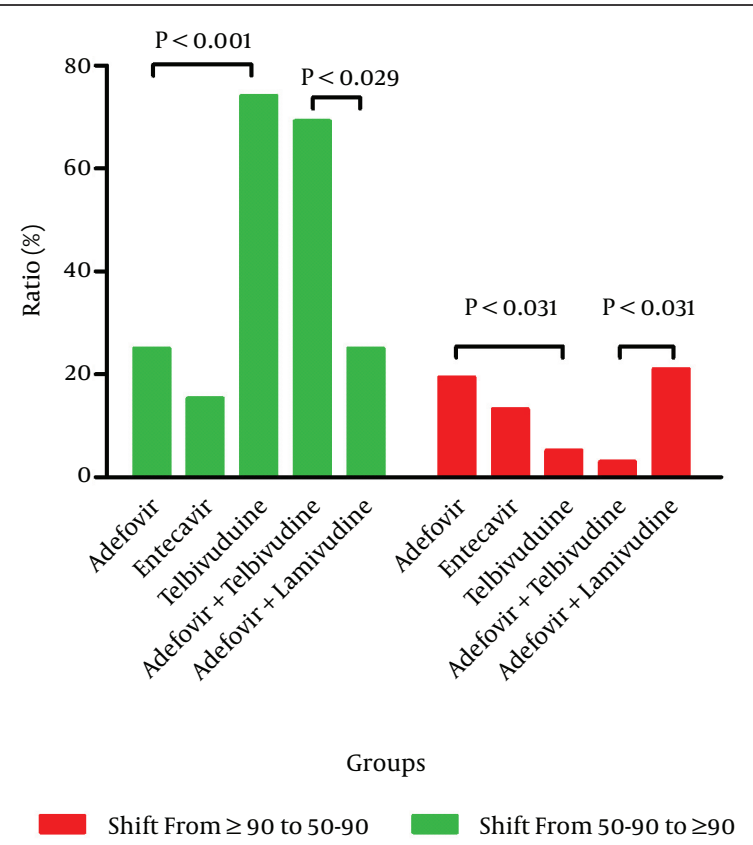

The P values were calculated using the chi-square test and Fisher's exact test for the monotherapy group and combination treatment group, respectively.

function of patients with low eGFR values. The patients in each drug group were classified into two subgroups based on their baseline eGFR values, namely, those with values of $50-90 \mathrm{~mL} / \mathrm{min}$ and $\geq 90 \mathrm{~mL} / \mathrm{min}$. The subanalysis of the patients with a baseline eGFR of $50-90 \mathrm{~mL} /$ min demonstrated that $74.07 \%$ of the patients (20 of 27 ) receiving telbivudine exhibited an improvement in eGFR values to $\geq 90 \mathrm{~mL} / \mathrm{min}$ after 24 months of treatment. In comparison, only $25.00 \%$ ( 2 of 8 ) of the patients in the adefovir group and only $15.38 \%$ ( 2 of 13 ) of the patients in the entecavir group exhibited this improvement (Figure 4). The same subanalysis of the patients in the two combination groups indicated that the percentage of patients with renal function improvement was $69.23 \%$ (9 of 13 ) in the adefovir plus telbivudine group but only $25.00 \%$ (5 of 20) in the adefovir plus lamivudine group. Among the patients with baseline eGFR values of $\geq 90 \mathrm{~mL} / \mathrm{min}$, $94.74 \%$ of the patients ( 90 of 95) in the telbivudine group, $80.56 \%$ (29 of 36) of the patients in the adefovir group, and $86.79 \%$ (46 of 53) of the patients in the entecavir group maintained stable renal function (eGFR $\geq 90 \mathrm{~mL}$ / min) after 24 months of treatment. Similarly, the percentage of patients retaining stable renal function in the adefovir plus telbivudine group was $96.97 \%$ (32 of 33), which was significantly higher than the percentage $(78.95 \%, 30$ of 38) in the other drug combination group. The eGFR values demonstrate that both telbivudine monotherapy and combination therapy with adefovir plus telbivudine therapy are beneficial to renal function. 
Jiang L et al.

\begin{tabular}{|c|c|c|c|}
\hline Effect & Estimate & Standard Error & P Value \\
\hline Gender (male vs. female) & -1.64 & 0.61 & 0.008 \\
\hline Age & -0.08 & 0.03 & 0.005 \\
\hline Baseline eGFR & -0.16 & 0.02 & $<0.001$ \\
\hline HBeAg (negative vs. positive) & -0.34 & 0.53 & 0.527 \\
\hline Compensated cirrhosis & 0.40 & 0.60 & 0.507 \\
\hline Telbivudine & 6.41 & 1.02 & $<0.001$ \\
\hline Entecavir & 1.54 & 1.13 & 0.174 \\
\hline
\end{tabular}

${ }^{\mathrm{a}}$ The adefovir group was set as the control group in the linear mixed effects model.

\begin{tabular}{lccc}
\hline Table 4. Predictors of eGFR (aMDRD) & Change From Baseline in the Combination Therapy Groups ${ }^{\mathrm{a}}$ & \\
\hline Effect & Estimate & Standard Error & P Value \\
\hline Gender (male vs. female) & -3.65 & 1.07 & 0.001 \\
Age & -0.18 & 0.06 & 0.003 \\
Baseline eGFR & -0.28 & 0.04 & $<0.001$ \\
HBeAg (negative vs. positive) & 0.34 & 1.07 & 0.750 \\
Compensated cirrhosis & -0.23 & 1.28 & 0.861 \\
Adefovir + telbivudine & 5.78 & 1.19 & $<0.001$ \\
\hline
\end{tabular}

${ }^{\mathrm{a}}$ The adefovir + lamivudine group was set as the control group in the linear mixed effects model.

\subsection{Predictive Factors Related to Significant eGFR Changes}

In the linear mixed effects model for the three monotherapy groups, medication, age, gender, and baseline eGFR were significant predictors of eGFR changes over time (Table 3 ). As the strongest factor in predicting eGFR changes $(\mathrm{P}<0.001)$, telbivudine improved renal function compared with the control drug (adefovir). The benefit of telbivudine was more evident in women than in men $(\mathrm{P}=0.008)$, and the baseline eGFR values were negatively correlated with eGFR changes $(\mathrm{P}<0.001)$. In the linear mixed effects model for the two combination groups, these four variables (medication, age, gender, and baseline eGFR) were also capable of predicting eGFR changes over time (Table 4). The adefovir plus telbivudine group exhibited an eGFR increase compared with the control level (adefovir plus lamivudine). Therefore, telbivudine is renoprotective when used in both monotherapy and combination therapy.

\subsection{Relationships Between CK Increase and eGFR Improvement}

Patients in the telbivudine monotherapy group were divided into five subgroups based on the documented times of CK abnormality during the 2-year treatment period. The eGFR changes from the baseline values to the values at month 24 among these five subgroups were analyzed through one-way analysis of variance, and no significant differences were found $(P=0.992)$. Thus, the renoprotective action of telbivudine does not correlate with the abnormal CK levels.

\section{Discussion}

Several studies demonstrated that adefovir impairs renal function during the treatment of HBV infection (5, $6,21)$. It has been recently reported that telbivudine improves renal function (10), but patients who encounter HBV resistance to lamivudine or telbivudine are required to add adefovir to their drug regimens. The effects of the combination therapies on renal function are thus important issues. Our study reveals that both monotherapy and combination therapy with telbivudine improve renal function during the treatment of HBV infection. Moreover, the eGFR improvement during telbivudine monotherapy is not correlated with abnormal CK levels.

Although some of our results are consistent with previous findings, we have employed a completely different method of analysis. It is noteworthy that previous exposure to lamivudine or telbivudine may exert a long-term influence on renal function, which was taken into consideration in our study. We included a telbivudine group within the patient group undergoing monotherapy regimens, and we included an adefovir-plus-telbivudine group within the patient group receiving the combination treatment regimens. In both the monotherapy and 
combination regimen groups, telbivudine proved to be accompanied by a strong eGFR increase. We further found that eGFR changes did not correlate with CK abnormalities during telbivudine monotherapy. This observation is consistent with the previous findings of the GLOBE study (17), but our conclusion is based on a different methodology. The $\mathrm{CK}$ values of patients were recorded at 5 time points during two years of monotherapy with telbivudine, and the numbers of incidents of CK elevations in each patient were subsequently calculated. According to these incidences $(0,1,2,3$, and 4$)$, the patients in the telbivudine monotherapy group were divided into five groups, and the eGFR changes in the five groups were compared.

The patients in each group were divided into two subgroups, namely, those with an eGFR $\geq 90$ and those with an eGFR between 50 and $90 \mathrm{~mL} / \mathrm{min}$. In the case of telbivudine monotherapy and combination therapy, 74.07\% and $69.23 \%$, respectively, of the patients with baseline eGFR values that were between 50 and $90 \mathrm{~mL} / \mathrm{min}$ exhibited improved values of $\geq 90 \mathrm{~mL} / \mathrm{min}$ after 24 months of treatment. These findings further demonstrate the powerful renoprotective effect of telbivudine. Mild renal impairment is defined as an eGFR value that is at least 60 but less than $90 \mathrm{~mL} / \mathrm{min}$. However, patients receiving nucleos $(\mathrm{t})$ ide analogue therapies for CHB require adjusted doses and/or intervals of antiviral drugs when their eGFR value is less than $50 \mathrm{~mL} / \mathrm{min}$, according to the EASL Clinical Practice Guidelines (1). A critical value of 50 $\mathrm{mL} / \mathrm{min}$ is therefore appropriate in the study of the renal function of patients with CHB.

Patients with eGFR values between 50 and $90 \mathrm{~mL} / \mathrm{min}$ are at great risk for progressive renal dysfunction (or end-stage renal disease) (22). Compensated liver cirrhosis and an age $\geq 50$ years are also risk factors for kidney disease. The renal safety of these three subpopulations during long-time antiviral treatment is an important issue. Therefore, we examined the eGFR changes from baseline to month 24 in these three subpopulations for each treatment regimen. We found that these three subpopulations had the best eGFR increases when they were treated with telbivudine or adefovir plus telbivudine. Telbivudine administered as either monotherapy or combination therapy is an effective treatment option for patients with these renal risk factors. However, further study is required to determine whether telbivudine is renoprotective in patients with decompensated hepatic cirrhosis or other advanced liver diseases.

It is noteworthy that despite the nephrotoxicity of adefovir, combination therapy with adefovir and telbivudine elicits a greater eGFR increase than telbivudine monotherapy. Both adefovir and telbivudine are metabolized by the kidneys, but the renal effects differ. Telbivudine may be beneficial to renal function through the reduction of serum angiotensin-converting enzyme (ACE) levels (23), whereas adefovir-induced nephrotoxicity is mediated by the depletion of mitochondrial DNA
(mtDNA) in proximal tubular cells through the inhibition of mtDNA replication (24). The renoprotective effect of the adefovir plus telbivudine combination resulting from the decrease in serum ACE induced by telbivudine is perhaps more significant in the existence of adefovirinduced mtDNA inhibition. The observed eGFR improvements in the three subpopulations at high renal risk during telbivudine treatment and the eGFR increases found in patients receiving telbivudine plus adefovir therapy indicate that telbivudine therapy is accompanied by significant eGFR elevations in patients at high renal risk (including the risk of nephrotoxicity from adefovir).

Entecavir monotherapy is also accompanied by a reduction of serum ACE levels (23); however, we found that entecavir monotherapy decreases renal function to a small extent. There may be unrecognized mechanisms by which entecavir impairs renal function. Treatment with the adefovir plus lamivudine combination also causes eGFR to decline, in accordance with previous studies (7, 25). Apparently, lamivudine, unlike telbivudine, cannot overcome adefovir-induced nephrotoxicity. Nevertheless, patients diagnosed with HBV-GN show improvement in their renal function after taking antiviral drugs such as lamivudine and entecavir $(16,26)$. In these patients, the benefit of the medication in preventing virus-induced severe renal impairment is greater than the slight renal toxicity caused by the drug itself.

In addition, the factors influencing the eGFR changes were analyzed by means of two linear mixed effects models for both the monotherapy and combination therapy groups. Both models indicated that age, female gender, and medication are significant factors for predicting eGFR increases. Both telbivudine monotherapy and combination treatment are the strongest predictors of eGFR increases. In contrast, the baseline eGFR is negatively correlated with the 2-year eGFR changes, indicating that patients with lower baseline eGFR levels are more prone to eGFR increases.

Although our study has some drawbacks: small sample size, short follow-up time, not taking into account the clinical efficacy of the antiviral drug. It still confirms the positive effect of telbivudine on the renal function of $\mathrm{CHB}$ patients. The benefit is particularly evident when telbivudine is combined with adefovir, which is nephrotoxic when used alone. The benefit is also evident in patients who are at a high risk of renal disease for reasons such as compensated liver cirrhosis or an age of more than 50 years. Furthermore, the benefit is evident in patients with initial renal impairment (eGFR of at least 50 but less than $90 \mathrm{~mL} / \mathrm{min}$ ). The findings provide significant guidance for clinical medication decisions. It is reported that the serum ACE levels in CHB patients treated with telbivudine decrease from their baseline values and that the ACE levels are negatively correlated with the eGFR values. These observations may partially explain the renoprotective effect of telbivudine. However, the full mechanism has not yet been elucidated. 


\section{Acknowledgments}

We thank Ping Yin (from Tongji Medical College, Huazhong University of Science and Technology, Wuhan, China) for helpful discussion and all the anonymous reviewers for their helpful suggestions on the quality improvement of our paper.

\section{Footnotes}

Authors' Contribution:Libin Jiang produced tables and figures, and drafted the manuscript; Song $\mathrm{Hu}$ and Man He reviewed the literature, collected and interpreted the clinical data; Libin Jiang assembled and interpreted the clinical data; Deying Tian attended the data analysis; Libin Jiang and Deying Tian conceived the study and made the revision; All authors finalized the manuscript and have read and approved the final manuscript.

Funding/Support:This work was funded by the author themselves.

\section{References}

1. European Association For The Study Of The L. EASL clinical practice guidelines: Management of chronic hepatitis B virus infection. J Hepatol. 2012;57(1):167-85. doi: 10.1016/j.jhep.2012.02.010. [PubMed: 22436845]

2. Liaw YF, Leung N, Kao JH, Piratvisuth T, Gane E, Han KH, et al. Asian-Pacific consensus statement on the management of chronic hepatitis B: a 2008 update. Hepatol Int. 2008;2(3):263-83. doi:10.1007/s12072-008-9080-3. [PubMed:19669255]

3. Papatheodoridis GV, Manolakopoulos S, Dusheiko G, Archimandritis AJ. Therapeutic strategies in the management of patients with chronic hepatitis B virus infection. Lancet Infect Dis. 2008;8(3):167-78. doi: 10.1016/S1473-3099(07)70264-5. [PubMed: 18053766]

4. Fontana RJ. Side effects of long-term oral antiviral therapy for hepatitis B. Hepatology. 2009;49(5 Suppl):S185-95. doi: 10.1002/ hep.22885. [PubMed: 19399802]

5. Izzedine H, Isnard-Bagnis C, Hulot JS, Vittecoq D, Cheng A, Jais CK, et al. Renal safety of tenofovir in HIV treatment-experienced patients. AIDS. 2004;18(7):1074-6. [PubMed: 15096814]

6. Hadziyannis SJ, Tassopoulos NC, Heathcote EJ, Chang TT, Kitis $\mathrm{G}$, Rizzetto $\mathrm{M}$, et al. Long-term therapy with adefovir dipivoxil for HBeAg-negative chronic hepatitis B. $N$ Engl J Med. 2005;352(26):2673-81. doi: 10.1056/NEJMoa042957. [PubMed: 15987916]

7. Lampertico P, Vigano M, Manenti E, Iavarone M, Sablon E, Colombo M. Low resistance to adefovir combined with lamivudine: a 3-year study of 145 lamivudine-resistant hepatitis B patients. Gastroenterology. 2007;133(5):1445-51. doi: 10.1053/j.gastro.2007.08.079. [PubMed:17983801]

8. Nelson MR, Katlama C, Montaner JS, Cooper DA, Gazzard B, Clotet $\mathrm{B}$, et al. The safety of tenofovir disoproxil fumarate for the treatment of HIV infection in adults: the first 4 years. AIDS. 2007;21(10):1273-81. doi: 10.1097/QAD.0b013e3280b07b33. [PubMed: 17545703]

9. Mauss S, Berger F, Schmutz G. Antiretroviral therapy with tenofovir is associated with mild renal dysfunction. AIDS. 2005;19(1):935. [PubMed:15627039]

10. Gane EJ, Deray G, Liaw YF, Lim SG, Lai CL, Rasenack J, et al. Telbivudine improves renal function in patients with chronic hepatitis B. Gastroenterology. 2014;146(1):138-146 e5. doi: 10.1053/j.gas- tro.2013.09.031. [PubMed: 24067879]

11. Cholongitas E, Vasiliadis T, Goulis I, Fouzas I, Antoniadis N, Papanikolaou $\mathrm{V}$, et al. Telbivudine is associated with improvement of renal function in patients transplanted for HBV liver disease. $J$ Viral Hepat. 2015;22(7):574-80. doi: 10.1111/jvh.12362. [PubMed: 25385239]

12. Amet S, Bronowicki JP, Thabut D, Zoulim F, Bourliere M, Mathurin $\mathrm{P}$, et al. Prevalence of renal abnormalities in chronic HBV infection: the HARPE study. Liver Int. 2015;35(1):148-55. doi: 10.1111/ liv.12480. [PubMed:24502506]

13. Bhimma R, Coovadia HM. Hepatitis B virus-associated nephropathy. Am J Nephrol. 2004;24(2):198-211. doi: 10.1159/000077065. [PubMed:14988643]

14. Zou XJ, Jiang XQ, Tian DY. Clinical features and risk factors of creatine kinase elevations and myopathy associated with telbivudine. J Viral Hepat. 2011;18(12):892-6. doi: 10.1111/j.13652893.2010.01412.x. [PubMed:22093034]

15. Hsu HC, Lin GH, Chang $\mathrm{MH}$, Chen $\mathrm{CH}$. Association of hepatitis B surface (HBs) antigenemia and membranous nephropathy in children in Taiwan. Clin Nephrol. 1983;20(3):121-9. [PubMed: 6354538]

16. Tang S, Lai FM, Lui YH, Tang CS, Kung NN, Ho YW, et al. Lamivudine in hepatitis B-associated membranous nephropathy. Kidney Int. 2005;68(4):1750-8. doi: 10.1111/j.1523-1755.2005.00591.x. [PubMed: $16164651]$

17. Lai CL, Gane E, Liaw YF, Hsu CW, Thongsawat S, Wang Y, et al. Telbivudine versus lamivudine in patients with chronic hepatitis $\mathrm{B}$. N Engl J Med. 2007;357(25):2576-88. doi: 10.1056/NEJMoa066422. [PubMed:18094378]

18. Peng CY, Chien RN, Liaw YF. Hepatitis B virus-related decompensated liver cirrhosis: benefits of antiviral therapy. $J$ Hepatol. 2012;57(2):442-50. doi: 10.1016/j.jhep.2012.02.033. [PubMed: 22504333]

19. Levey AS, Coresh J, Balk E, Kausz AT, Levin A, Steffes MW, et al. National Kidney Foundation practice guidelines for chronic kidney disease: evaluation, classification, and stratification. Ann Intern Med. 2003;139(2):137-47. [PubMed:12859163]

20. Levey AS, Stevens LA, Schmid CH, Zhang YL, Castro A3, Feldman $\mathrm{HI}$, et al. A new equation to estimate glomerular filtration rate. Ann Intern Med. 2009;150(9):604-12. [PubMed:19414839]

21. Ha NB, Ha NB, Garcia RT, Trinh HN, Vu AA, Nguyen HA, et al. Renal dysfunction in chronic hepatitis B patients treated with adefovir dipivoxil. Hepatology. 2009;50(3):727-34. doi: 10.1002/hep.23044. [PubMed: 19517525]

22. Keith DS, Nichols GA, Gullion CM, Brown JB, Smith DH. Longitudinal follow-up and outcomes among a population with chronic kidney disease in a large managed care organization. Arch Intern Med. 2004;164(6):659-63. doi: 10.1001/archinte.164.6.659. [PubMed:15037495]

23. Liang KH, Chen YC, Hsu CW, Chang ML, Yeh CT. Decrease of serum Angiotensin converting enzyme levels upon telbivudine treatment for chronic hepatitis B virus infection and negative correlations between the enzyme levels and estimated glumerular filtration rates. Hepat Mon. 2014;14(1):e15074. doi: 10.5812/hepatmon.15074. [PubMed: 24596580]

24. Tanji N, Tanji K, Kambham N, Markowitz GS, Bell A, D'Agati V D. Adefovir nephrotoxicity: possible role of mitochondrial DNA depletion. Hum Pathol. 2001;32(7):734-40. doi: 10.1053/ hupa.2001.25586. [PubMed: 11486172]

25. Thurairajah P, Khanna A, Mutimer D. Add-on combination therapy with adefovir dipivoxil induces renal impairment in patients with lamivudine-refractory hepatitis B virus (J Viral Hepat 2010 Feb 1;17(2):123-9). J Viral Hepat. 2011;18(11):820. doi: 10.1111/j.13652893.2010.01388.x. [PubMed: 21054684]

26. Yang YF, Xiong QF, Zhao W, Zhong YD. Complete remission of hepatitis B virus-related membranous nephropathy after entecavir monotherapy. Clin Res Hepatol Gastroenterol. 2012;36(5):e8992. doi:10.1016/j.clinre.2012.03.033. [PubMed:22572521] 